\title{
Formulation and Evaluation of Microemulsion Based Luliconazole Gel for Topical Delivery
}

\author{
Panchaxari Mallappa Dandagi, Pratibha Pandey*, Anand Panchakshari Gadad, Vinayak Shivamurthy \\ Mastiholimath
}

Department of Pharmaceutics, KLE College of Pharmacy (A constituent unit of KAHER), Nehru Nagar, Belagavi, Karnataka, INDIA.

\begin{abstract}
Introduction: Drug delivery through topical route is mostly preferred for local dermatological action. Topical action of preparations has certain limitations in terms of drug solubility, residence time, lipophilicity and permeability. Conventional dosage forms such as creams, ointments etc exhibit drawbacks like problem in stability, stickiness, poor absorption as well as permeation mainly in case of large molecule. To overcome this, the origination of emulgel came into existence which basically focus on the delivery of hydrophobic drugs. ${ }^{1}$ The present research is proposed to prepare and evaluate microemulsion based luliconazole gel for its enhanced solubility and permeability for better antifungal activity. Materials and Methods: The present study was aimed to prepare and evaluate microemulgel of luliconazole for topical application by using poly unsaturated fatty acids such as linseed oil. Sodium alginate was used as a gelling agent. Luliconazole microemulsion was prepared by varying the concentration of surfactants while the oil concentration was kept fixed. It was characterized for globule size and physical stability. Microemulgel was prepared and characterized for drug content, viscosity, spreadability, in vitro permeation study, skin irritation test, in vitro antifungal study and stability study. Skin irritation test was carried out after taking approval of Institutional Animal Ethics Committee. Results and Discussion: Two microemulsion were selected based on the globule area, PDI and physical stability and incorporated into the gel base of sodium alginate. The optimized microemulgel (F1) showed acceptable physical properties with lowest viscosity value $(2325 \mathrm{cps})$ and showed pseudoplastic behaviour, highest spreadability value $(3.7 \mathrm{gm} . \mathrm{cm} / \mathrm{sec})$, Highest drug permeation $(63.50 \%)$ after $5 \mathrm{hr}$. Skin irritation test showed no signs of irritation in any rats. Optimized formulation F1 represents greater zone of inhibition $(38 \mathrm{~mm})$ as compared to pure gel $(34 \mathrm{~mm})$ and showed acceptable stability profile. Conclusion: It can be concluded that luliconazole microemulgel prepared with linseed oil and sodium alginate can be a choice for topical antifungal treatment.
\end{abstract}

Key words: Luliconazole, Linseed oil, Sodium alginate, Microemulsion, Topical, Antifungal, in vitro permeation.

\section{INTRODUCTION}

Microemulgel is considered as one of the promising technologies among novel drug delivery system due to its dual mechanism via emulsion and gel. Moreover, it was observed that by combining emulsion with gel, its stability increased according to Pottalaswathi et al. The reason behind choosing microemulsion system was its excellent capacity to solubilize and also its capability to permeate into the skin. ${ }^{2,3}$ Linseed oil belongs to the category of polyunsaturated fatty acids that provides dual action i.e, increases solubility as well as permeability. Moreover, it is non-toxic and limits the evaporation of water from the surface. Sodium alginate is an anionic, naturally biodegradable polymer with good biocompatibility. It has comparatively low cost and provides good mechanical strength. ${ }^{4}$

Microemulgel preparation requires screening of oils, surfactant and co-surfactant. Based on the solubility profile of
Submission Date: 31-05-2019; Revision Date: 26-11-2019; Accepted Date: 07-11-2019

DOI: 10.5530/ijper.54.2.34 Correspondence: Ms. Pratibha Pandey, Department of

Pharmaceutics, KLE College of Pharmacy, Nehru Nagar, Belagavi-590010, Karnataka, INDIA.

Phone: +91 8312444444 E-mail: cool.pratibha25@ gmail.com

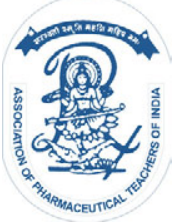

www.ijper.org 
API, selection of these are carried out. ${ }^{5}$ Presence of oil leads to more penetration of API in the skin. Microemulsions helps in keeping the drug in solubilized form and the formation of small sized droplets provides large interfacial area for drug absorption. ${ }^{6}$

The present research is proposed to prepare and evaluate microemulsion based luliconazole gel for its enhanced solubility and permeability for better antifungal activity by using polyunsaturated fatty acids such as linseed oil and sodium alginate as gel base.

\section{MATERIALS AND METHODS}

\section{Materials}

Luliconazole was purchased from Aksharam chemicals, Ahmedabad. Linseed oil, Neem oil and olive oil were procured from Loba Chemie Private Ltd, Mumbai. Sodium alginate, Tween 20, Tween 80, Span 20 and Span 80 was procured from M/s Hi-media Pvt limited Mumbai. Propylene glycol was procured from Nice chemicals Kerala and PEG 400 was procured from Merck Specialities Private Ltd, Mumbai. All the chemicals used were of analytical grade.

\section{Methods}

\section{Preparation of Luliconazole microemulsion}

For formulating microemulsion, Span 20 concentration used in $(\mathrm{E} 1=1 \%, \mathrm{E} 2=0.75 \%, \mathrm{E} 3=0.5 \%, \mathrm{E} 4=0.85 \%)$ along with drug $(5 \%)$ was dissolved in linseed oil $(5 \%)$ which gives the oil phase. For preparation of aqueous phase, Tween 20 in concentration $(\mathrm{E} 1=0.25 \%, \mathrm{E} 2=0.5 \%$, $0.75 \%, \mathrm{E} 4=0.4 \%)$ was dissolved in purified water. The concentration of oil and surfactants were selected based on HLB value. Both the phases were kept on water bath and separately heated at $70-80^{\circ} \mathrm{C}$. Both the phases were combined with continuous stirring for $15 \mathrm{~min}$ at $5 \mathrm{rpm}$ and cooled to room temperature. ${ }^{7,8}$

\section{Globule size determination}

For determining the globule size of emulsions, Dynamic light scattering particle size analyser (Nanotrac A-150) was used. It detects the particle size from the range of $0.08 \mathrm{~nm}$ to $6.8 \mu \mathrm{m}$. Dilution was made by taking $1 \mathrm{ml}$ emulsion and diluted to $20 \mathrm{ml}$ with millipore water and readings were taken. ${ }^{9}$ Readings were taken in triplicate.

\section{Physical stability of microemulsion}

Microemulsion stability was carried out by processing it for centrifugation for $15 \mathrm{~min}$ at $3000 \mathrm{rpm}$. Any changes like phase separation and clarity was observed visually. Stability against freeze through cycle or heating and cooling cycle was not conducted as centrifugation process showed the desired results. ${ }^{10}$

\section{Preparation of microemulgel}

For preparation of gel base, sodium alginate in concentration of $(2 \%, 4 \%, 6 \%)$ was dispersed in sufficient amount of water and it was kept overnight. Formation of luliconazole microemulgel was done by incorporation of emulsion containing ( $\mathrm{g}$ luliconazole) into the gel base by continuous stirring at room temperature using magnetic stirrer at $3000 \mathrm{rpm}$ to remove any formation of lumps and to provide proper consistency to formulation.

\section{Evaluation of microemulgel \\ Drug content}

Drug content was calculated by dissolving $1 \mathrm{~g}$ of emulgel into $100 \mathrm{ml}$ of acetate buffer of $\mathrm{pH} \mathrm{5.5}$. From this $1 \mathrm{ml}$ was withdrawn and diluted upto $10 \mathrm{ml}$ with acetate buffer. Since the luliconazole was insoluble in water, acetate buffer was used as it showed highest solubility in acetate buffer. This solution was subjected to sonication for $30 \mathrm{~min}$ and filtered. No precipitation of drug was observed as it dissolved completely after sonication. Measured the absorbance spectrophotometrically at $272 \mathrm{~nm} .{ }^{11}$

\section{$\mathrm{pH}$}

Digital $\mathrm{pH}$ meter was used for determination of $\mathrm{pH}$. For measurement of $\mathrm{pH}$, firstly the $\mathrm{pH}$ electrode was calibrated using acetate buffer $\mathrm{pH} 5.5$ and $1 \%$ aqueous solution of formulation was taken and electrode was immersed into the microemulgel formulation till the fluctuation in readings stopped and a constant reading was obtained. ${ }^{11}$

\section{Viscosity}

Brookfield viscometer cap 2000+ was employed for measurement of viscosity. Approximately $1 \mathrm{~g}$ of emulgel was taken on the plate of Brookfield viscometer and it was allowed to settle for 5-10 min and then spindle was placed on the plate containing gel and rotated at a speed of $5 \mathrm{rpm}$ with the help of spindle. The temperature was maintained at $25^{\circ} \mathrm{C}$ and corresponding dial reading was noted down. Reading indicates the viscosity of the formulations in cps. ${ }^{12}$

\section{Spreadability}

Spreadability was performed by using two glass slides of length $7.5 \mathrm{~cm} .350 \mathrm{mg}$ of microemulgel was weighed accurately and it was taken on one glass slide. Another glass slide was placed above it from a height of $5 \mathrm{~cm}$. A weight of $5 \mathrm{gm}$ was kept on the upper slide and after 1 
min, diameter of circle that was spread was noted in $\mathrm{cm}$. The observed diameter indicates the type of gel. ${ }^{13}$

\section{In vitro permeation study}

The study was performed by modified Franz diffusion cell using dialysis membrane. Before carrying out the study, membrane was kept in acetate buffer $\mathrm{pH} 5.5$ for $24 \mathrm{hr}$ and it was mounted carefully between the donor and receptor chamber. $200 \mathrm{mg}$ of emulgel was weighed and homogeneity spread on the dialysis membrane. $12 \mathrm{ml}$ of acetate buffer ( $\mathrm{pH}$ 5.5) was placed in receptor medium as dissolution media. Both donor and receptor compartment were kept in contact with each other and whole assembly was maintained at constant temperature of $32 \pm 0.5^{\circ} \mathrm{C}$. Magnetic bead was used to stirred the solution of receptor chamber. $1 \mathrm{ml}$ of sample was withdrawn after specific time intervals and equal amount was replaced with fresh dissolution media. Sample absorbance was calculated spectrophotometrically at $272 \mathrm{~nm}$ and \% cumulative drug permeation was calculated. ${ }^{14}$

In order to predict the drug release mechanism, the obtained values was fitted into various model like Zero order, First order, Higuchi matrix and Korsmeyer-Peppas model. Best fit model was selected according to highest $\mathrm{R}^{2}$ values obtained. ${ }^{13}$

\section{Skin irritation test}

The test was carried out according to OECD guidelines for in vitro skin irritation test No. 439. Wistar rats (12) of either sex was used to carry out skin irritation test. Selected rats were segregated into two groups i.e., control and test. Each group comprised of 6 animals. Back skin area of $5 \mathrm{~cm}^{2}$ of rats was shaved one day before the starting of the study. After $24 \mathrm{hr}$, control group was applied with gel base (without drug) and test group was applied with the optimized emulgel (F1) and rats were examined for any signs of irritation. Scores were given according to observed signs of irritation.

\section{In vitro antifungal study}

In vitro antifungal study was carried out using agar well diffusion technique (Cup-plate method). Mueller Hinton Hiveg agar was used as media for growth of fungal strain (Candida albicans) using Spread plate technique. $50 \mu \mathrm{l}$ of sample (F1 containing $1 \mathrm{~g}$ of luliconazole) and pure gel (containing only API with gel base) were placed in the wells of the petriplates and it was kept at $37^{\circ} \mathrm{C}$ for $72 \mathrm{hr}$ in incubators. Zone of inhibition was measured (in mm) in triplicates. ${ }^{15}$

\section{Stability study}

Short-term stability study was carried out (due to shortage of time) for optimized formulation. Formulation was exposed to different conditions of temperature as well as relative humidity $25^{\circ} \mathrm{C} / 60 \% \mathrm{RH}$ and $40^{\circ} \mathrm{C} / 65 \%$ $\mathrm{RH}$ for a period of 1 month. After 1 month, formulation was examined for any changes in $\mathrm{pH}$, rheological properties and drug permeation profiles. ${ }^{13}$

\section{RESULTS AND DISCUSSION}

In the present research work, an attempt has been made to prepare and evaluate microemulsion based luliconazole gel for its enhanced solubility and permeability for antifungal activity by using poly unsaturated fatty acids such as linseed oil. Semi-synthetic polymer i.e. sodium alginate was used as gelling agent.

\section{Formulation of Luliconazole microemulsion}

Four microemulsions E1, E2, E3 and E4 were formulated by varying the concentration of Tween 20 and Span 20 based on the general required HLB value for vegetable oils i.e., (4:2:1). [Table 1] Based on the solubility $(27.85 \mathrm{mg} / \mathrm{ml}), 1 \mathrm{~g}$ of luliconazole was added to the formulation. Linseed oil was used as oil phase, Tween 20 (with solubility of $23.84 \mathrm{mg} / \mathrm{ml}$ ) as hydrophilic surfactant and Span 20 (with solubility of $18.98 \mathrm{mg} / \mathrm{ml}$ ) as lipophilic surfactant. HLB value for E1 and E4 was found to be 12.77 and 13.89 respectively.

\section{Globule size determination}

By using Nanotrac, the globule size of microemulsion was determined. Based on the observed MA i.e., surface area distribution of globules and polydispersity index E1 and E4 were selected as optimized microemulsion with $273.7 \mathrm{~nm}$ and $189.6 \mathrm{~nm}$ and with PDI of 0.632 and 0.197 . [Table 3, Figure 5,6] The reason behind lowest globular area can be the HLB value of surfactants as described by Hosseini et al. in his work that lowest particle observed in the HLB value ranging from 11-13. The HLB value for emulsion E1 and E4 was 12.77 and 13.89 respectively. Thus, it can be concluded that particle size can be influenced by HLB value of surfactants. Another reason for this can be the incorporation of linseed oil in the formulation. Low PDI value indicates that uniformity in the globule size of formulation was more. The structure

\begin{tabular}{|c|c|c|c|c|}
\hline Ingredients & E1 & E2 & E3 & E4 \\
\hline Luliconazole (g) & $1(5 \%)$ & $1(5 \%)$ & $1(5 \%)$ & $1(5 \%)$ \\
\hline Tween 20 (\%) & 0.25 & 0.5 & 0.75 & 0.4 \\
\hline Span 20 (\%) & 1 & 0.75 & 0.5 & 0.85 \\
\hline Linseed oil (\%) & 5 & 5 & 5 & 5 \\
\hline Water (ml) q.s. & $20 \mathrm{ml}$ & $20 \mathrm{ml}$ & $20 \mathrm{ml}$ & $20 \mathrm{ml}$ \\
\hline
\end{tabular}




\begin{tabular}{|c|c|c|c|c|c|c|}
\hline \multicolumn{7}{|c|}{ Table 2: Formulation table for Luliconazole } \\
microemulgel. \\
$\begin{array}{c}\text { Ingredients } \\
\text { (\%w/w) }\end{array}$ & F1 & F2 & F3 & F4 & F5 & F6 \\
\hline $\begin{array}{c}\text { Luliconazole } \\
\text { emulsion } \\
\text { equivalent to } \\
\text { Luliconazole }\end{array}$ & $1 \mathrm{~g}$ & $1 \mathrm{~g}$ & $1 \mathrm{~g}$ & $1 \mathrm{~g}$ & $1 \mathrm{~g}$ & $1 \mathrm{~g}$ \\
\hline Sodium alginate & $2 \%$ & $4 \%$ & $6 \%$ & $2 \%$ & $4 \%$ & $6 \%$ \\
\hline Linseed oil & 5 & 5 & 5 & 5 & 5 & 5 \\
\hline Tween 20 & 0.25 & 0.25 & 0.25 & 0.4 & 0.4 & 0.4 \\
\hline Span 20 & 1 & 1 & 1 & 0.85 & 0.85 & 0.85 \\
\hline Propylene glycol & 5 & 5 & 5 & 5 & 5 & 5 \\
\hline Methyl Paraben & 0.03 & 0.03 & 0.03 & 0.03 & 0.03 & 0.03 \\
\hline Propyl Paraben & 0.01 & 0.01 & 0.01 & 0.01 & 0.01 & 0.01 \\
\hline Distilled water q.s. & 100 & 100 & 100 & 100 & 100 & 100 \\
\hline
\end{tabular}

\begin{tabular}{|c|c|c|}
\hline \multicolumn{3}{|c|}{ Table 3: Globule size and PDI of luliconazole } \\
miroemulsions. \\
\hline Formulation code & $\begin{array}{c}\text { Globule size } \\
\text { (nm) }\end{array}$ & $\begin{array}{c}\text { Polydispersity } \\
\text { index }\end{array}$ \\
\hline E1 & 273.7 & 0.632 \\
\hline E2 & 342.0 & 0.964 \\
\hline E3 & 480.0 & 0.763 \\
\hline E4 & 189.6 & 0.197 \\
\hline
\end{tabular}

of globules was observed by using optical microscope with magnification of 40X. [Figure 1]

\section{Physical stability of microemulsion}

It was visualized after centrifugation, that there was no separation of phases in E1 and E4. Slight coalescence appeared in case of E3 and E4 microemulsion. So based on the stability, E1 and E4 were selected as optimized emulsion.

\section{Preparation of microemulgel}

Optimized emulsion E1 and E4 were used for preparation of emulgel. Luliconazole emulsion equivalent to $1 \mathrm{~g}$ was added to gel matrix of sodium alginate using magnetic stirrer to remove any formation of lumps. Methyl and propyl paraben were mixed in propylene glycol and added to the gel base containing emulsion. Triethanolamine was used for adjusting $\mathrm{pH}$. Formulation $\mathrm{F} 1, \mathrm{~F} 2$ and $\mathrm{F} 3$ was prepared with $\mathrm{E} 1$ emulsion having sodium alginate concentration of $2 \%, 4 \%$ and $6 \%$ respectively while F4, F5 and F6 was prepared with E2 emulsion having sodium alginate concentration of $2 \%$, $4 \%$ and $6 \%$ respectively. [Table 2]. Sodium alginate concentration $(2 \%, 4 \%, 6 \%)$ was selected as most of the microemulgel were prepared by using these concentration only.
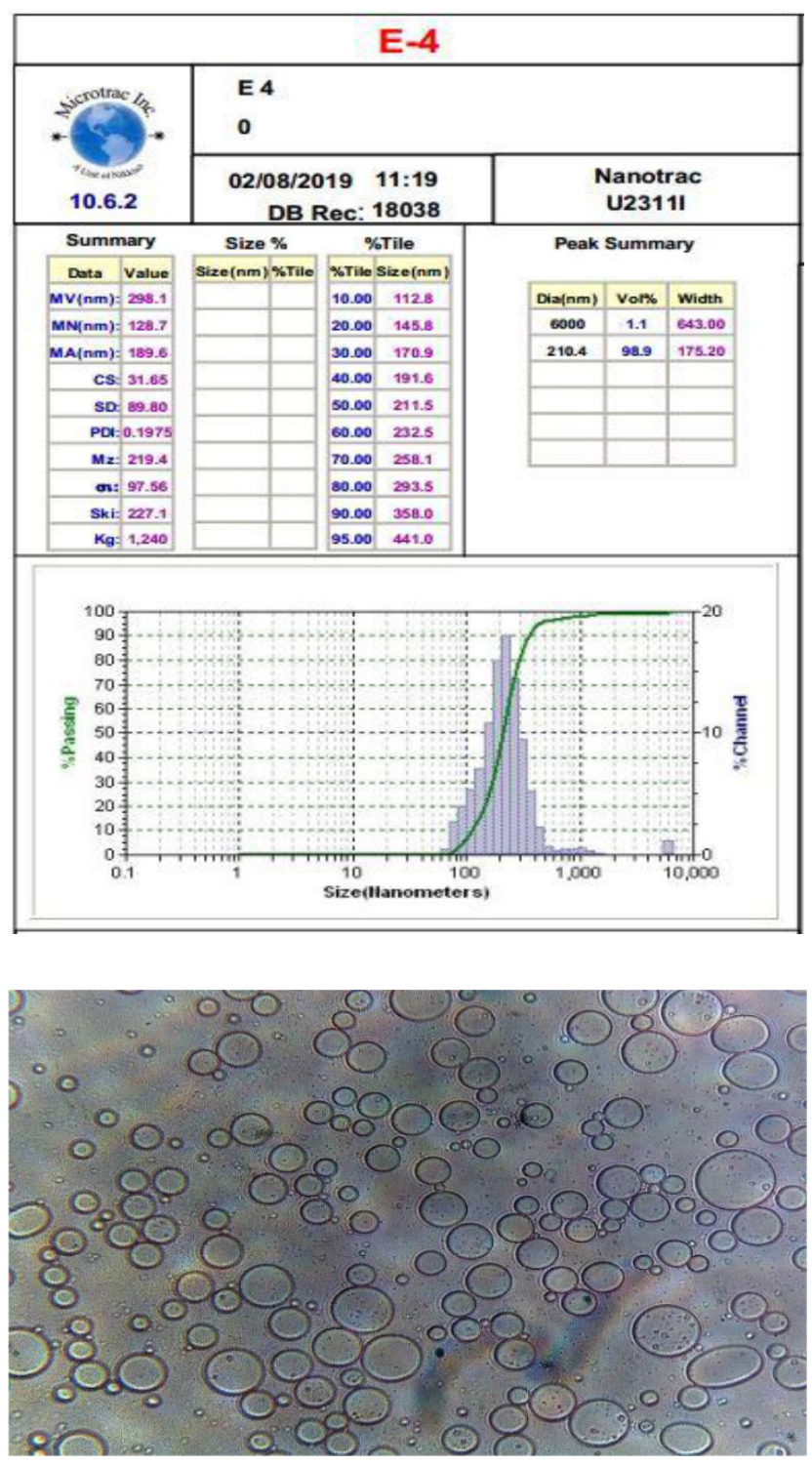

Figure 1: Photograph showing globular structure of microemulsion under 40x magnification.

\section{Drug Content}

The observed range of percentage drug content for all the formulation was from 74.77 to $95.49 \%$. [Table 4]. It was observed that with decrease in gelling agent concentration, drug content was found to be highest.

\section{pH}

All formulation showed $\mathrm{pH}$ within a range of 5.54 to 6.71 which is in accordance with $\mathrm{pH}$ of skin indicating skin compatibility and avoids any risk of skin irritation upon application. [Table 4]

\section{Viscosity}

The values of viscosity ranged from 2325 to 8850 . Lowest viscosity was exhibited by optimized formulation F1 i.e., 2325 formulated with $2 \%$ sodium alginate 
Table 4: Drug content and $\mathrm{pH}$ of formulations F1 to F6.

\begin{tabular}{|c|c|c|}
\hline Formulation code & Drug content ${ }^{*}(\%)$ & $\mathbf{p H}^{*}$ \\
\hline F1 & $95.49 \pm 1.22$ & $6.48 \pm 0.04$ \\
\hline F2 & $85.58 \pm 2.17$ & $6.51 \pm 0.22$ \\
\hline F3 & $74.77 \pm 1.47$ & $6.10 \pm 0.06$ \\
\hline F4 & $93.69 \pm 1.41$ & $5.83 \pm 0.08$ \\
\hline F5 & $84.68 \pm 1.52$ & $6.71 \pm 0.15$ \\
\hline F6 & $75.67 \pm 2.20$ & $5.54 \pm 0.11$ \\
\hline
\end{tabular}

*Data are expressed as Mean \pm S.D. $(n=3)$.

\begin{tabular}{|c|c|c|}
\hline \multicolumn{3}{|c|}{ Table 5: Viscosity, Spreadability of formulations } \\
F1 to F6. \\
\hline Formulation code & Viscosity (cps)* & $\begin{array}{c}\text { Spreadability* } \\
\text { (gm.cm/sec) }\end{array}$ \\
\hline F1 & $2325 \pm 271.44$ & $3.7 \pm 0.15$ \\
\hline F2 & $4087 \pm 361.74$ & $3.3 \pm 0.05$ \\
\hline F3 & $8850 \pm 312.24$ & $2.9 \pm 0.23$ \\
\hline F4 & $3975 \pm 474.92$ & $3.4 \pm 0.17$ \\
\hline F5 & $4275 \pm 354.22$ & $3.3 \pm 0.15$ \\
\hline F6 & $7350 \pm 114.56$ & $2.6 \pm 0.28$ \\
\hline
\end{tabular}

*Data are expressed as Mean \pm S.D. $(n=3)$.

concentration and E1 emulsion. It may be due to lower concentration of gelling agent employed in the formulation. Viscosity can directly influence the release profile of drug as increased viscosity can lead to more rigidity in the structure which can decline the rate of drug release. All luliconazole microemulgel exhibits pseudoplastic behaviour with shear thinning property as viscosity was found to decrease with increase in shear rate. [Table 5]

\section{Spreadability}

Spreadability values contributes to efficacy of formulation. The value of spreadability was found to be higher in case of optimized formulation F1 with $3.7 \mathrm{gm} . \mathrm{cm} / \mathrm{sec}$ whereas it was found lowest in case of F6 i.e., 2.6 gm.cm/sec. [Table 5] When the concentration of gelling agent decreased, the spreadability values was found to be increased. All the gels belong to fluid gel category [Table 6]. There was no ideal value for spredability reported in earlier studies. Based on the observed diameter, gels are classified.

\section{In vitro permeation study}

All the formulations showed percentage cumulative drug permeation within a range of $51.93 \%$ to $63.50 \%$ after 5 hr. [Figure 2] Maximum drug permeation was observed in case of F1 i.e., $63.50 \%$ with incorporation of E1 emulsion. The possible reason for this can be

\begin{tabular}{|c|c|}
\hline \multicolumn{2}{|c|}{ Table 6: Types of gel based on Spreadability values. } \\
\hline Types of gel & Measurement (in $\mathbf{c m}$ ) \\
\hline Fluid gel & More than 2.4 \\
\hline Semi- fluid gel & $1.9-2.4$ \\
\hline Semi stiff gel & $1.9-1.6$ \\
\hline Stiff gel & $1.6-1.4$ \\
\hline Very stiff gel & Less than 1.4 \\
\hline
\end{tabular}

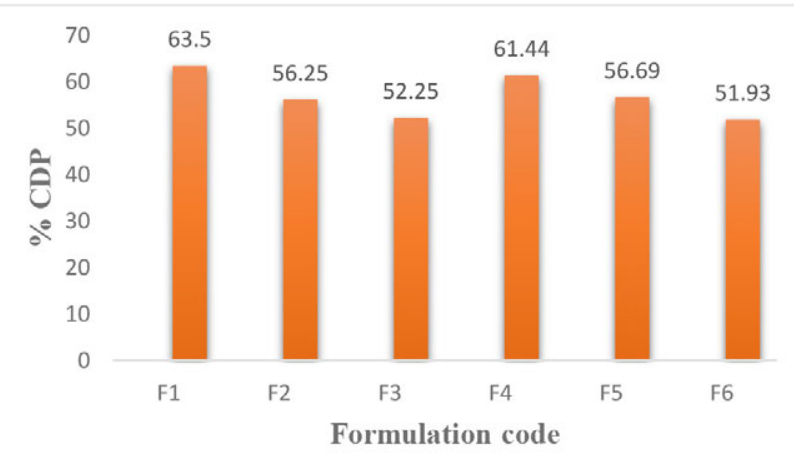

Figure 2: Comparison of in vitro percent cumulative drug permeation of all the formulations at the end of $5 \mathrm{hr}$.

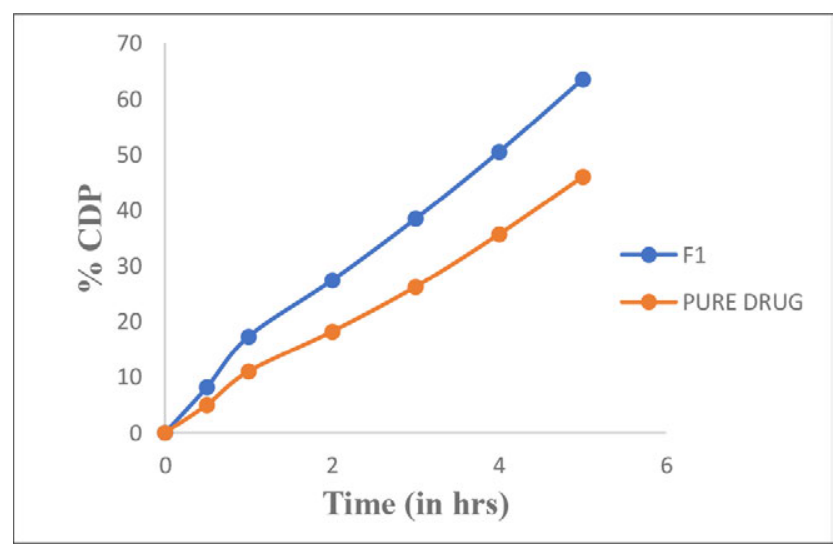

Figure 3: Comparison of in vitro permeation profile of optimized formulation F1 and pure drug.

the lower viscosity value found in F1 formulation. As discussed by Ayoub et al. that lower viscosity can lead to faster release of drug. Minimum drug permeation was observed in case of F6 (51.93\%) with 6\% sodium alginate concentration. This is because higher polymer concentration tends to develop more resistance for diffusion of drug by entrapment of drug molecules. Another reason for higher permeation of drug from F1 could be the presence of surfactant and co-surfactant which provides enhanced penetration of drug.

In vitro permeation study was also performed for pure gel (without excipients). After $5 \mathrm{hr}$, it showed permeation of $45.98 \%$ which is less than the optimized formulation F1. This is due to insolubility of luliconazole in water 
Table 7: In vitro release kinetics of formulations F1 to F6.

\begin{tabular}{|c|c|c|c|c|c|c|c|}
\hline \multirow{2}{*}{$\begin{array}{l}\text { FORMULATION } \\
\text { CODE }\end{array}$} & \multirow{2}{*}{$\begin{array}{c}\text { ZERO ORDER } \\
\left(R^{2}\right)\end{array}$} & \multirow{2}{*}{$\begin{array}{l}\text { FIRST ORDER } \\
\qquad\left(R^{2}\right)\end{array}$} & \multirow{2}{*}{$\begin{array}{l}\text { HIGUCHI MATRIX } \\
\left(R^{2}\right)\end{array}$} & \multirow{2}{*}{$\begin{array}{c}\text { HIXSON } \\
\text { CROWWELL }\left(R^{2}\right)\end{array}$} & \multicolumn{2}{|c|}{ PEPPAS } & \multirow{2}{*}{$\begin{array}{c}\text { BEST FIT } \\
\text { MODEL }\end{array}$} \\
\hline & & & & & $\left(R^{2}\right)$ & (n) & \\
\hline $\mathrm{F} 1$ & 0.9803 & 0.9779 & 0.8791 & 0.9872 & 0.9928 & 0.8311 & PEPPAS \\
\hline $\mathrm{F} 2$ & 0.9798 & 0.9815 & 0.8725 & 0.988 & 0.9935 & 0.7825 & PEPPAS \\
\hline F3 & 0.9816 & 0.9868 & 0.88 & 0.9909 & 0.9926 & 0.8465 & PEPPAS \\
\hline F4 & 0.9799 & 0.9805 & 0.8825 & 0.9885 & 0.9918 & 0.8812 & PEPPAS \\
\hline F5 & 0.981 & 0.9845 & 0.8819 & 0.9915 & 0.9924 & 0.8620 & PEPPAS \\
\hline F6 & 0.9792 & 0.9822 & 0.8674 & 0.9878 & 0.9967 & 0.7520 & PEPPAS \\
\hline
\end{tabular}

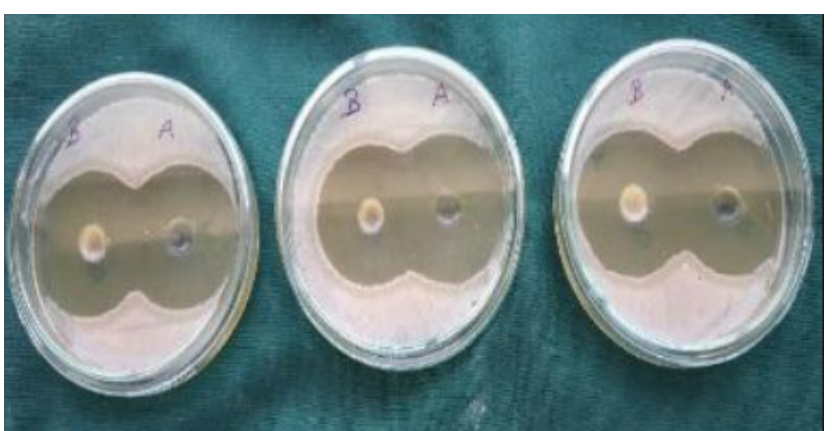

Figure 4: Showing zone of inhibition of optimized formulation F1 and pure drug.

A-Optimized formulation $F 1=38 \mathrm{~mm}$ B-Pure gel (without excipients) $=34 \mathrm{~mm}$

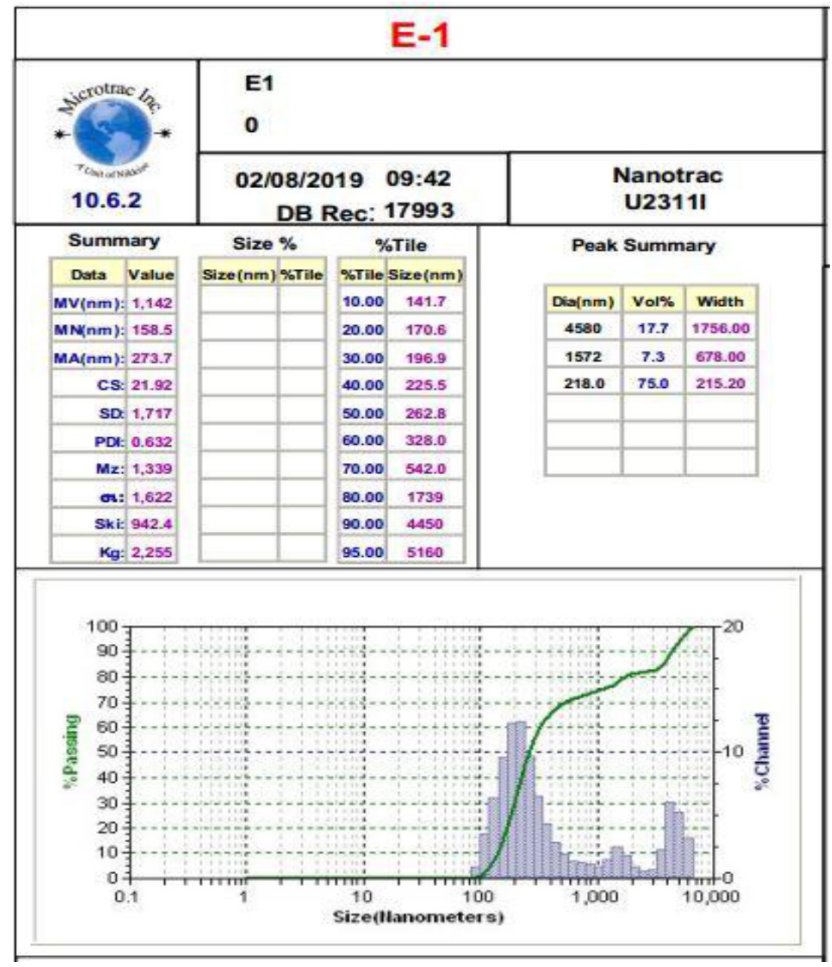

Figure 5: Globule size and PDI of optimized E1 Microemulsion

due to which drug was unable to dispersed within the gel matrix and permeation is retarded. [Figure 3] in vitro release kinetics of formulations F1 to F6. [Table 7]

\section{Skin irritation test}

Skin irritation test was carried out after taking approval of Institutional Animal Ethics Committee. Wistar rats (12) of either sex was used to carry out skin irritation test. Control group was treated with gel base without drug whereas test group was treated with optimized formulation F1. It was observed that both the groups showed no signs of irritation after $24 \mathrm{hr}$ and they were assigned with a score of 0 [Figure 7,8]. This indicates that the prepared formulation is safe for use.

\section{In vitro antifungal study}

In vitro antifungal study was carried out using agar well diffusion technique using Candida albicans strain for optimized formulation F1 and drug gel without surfactants and linseed oil. Optimized formulation F1 represents $38 \mathrm{~mm}$ zone of inhibition which is greater than

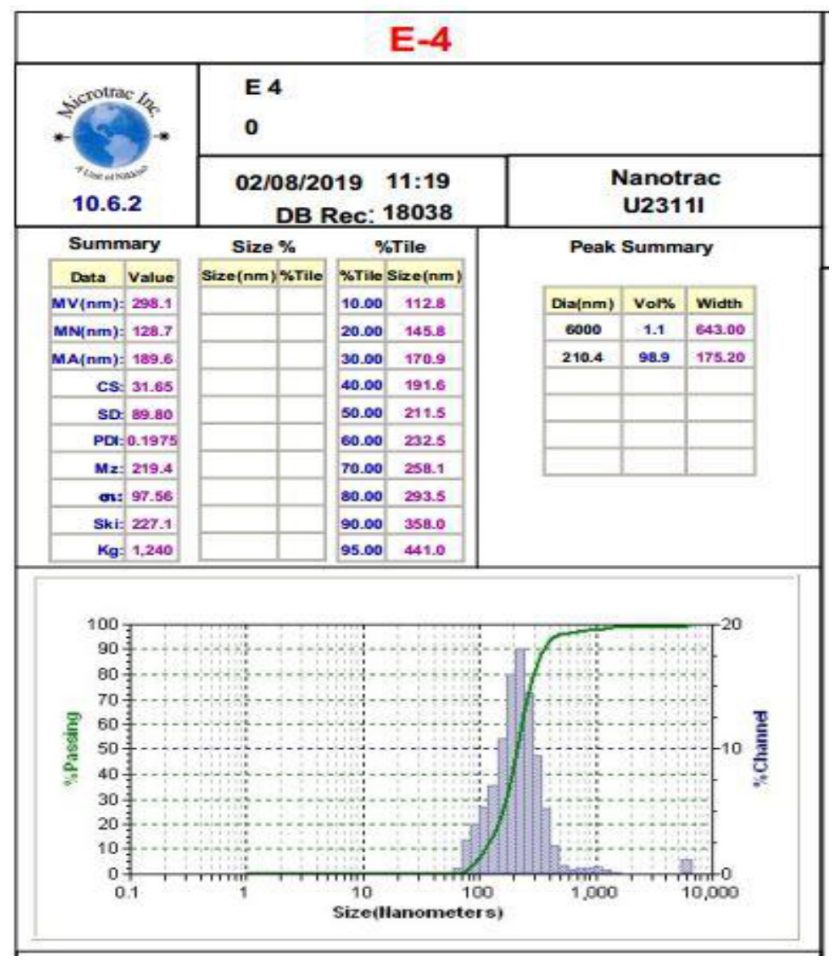

Figure 6: Globule size and PDI of optimized E4 Microemulsion. 
A - Control group after shaving

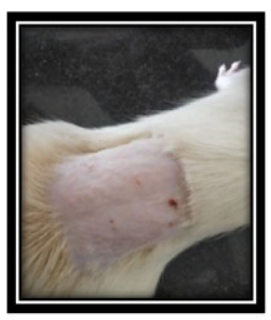

B -Test group after shaving
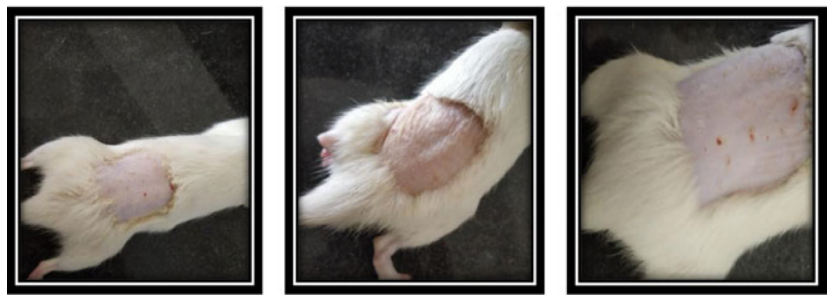

Figure 7: Skin irritaion test of Control and Test group after shaving.
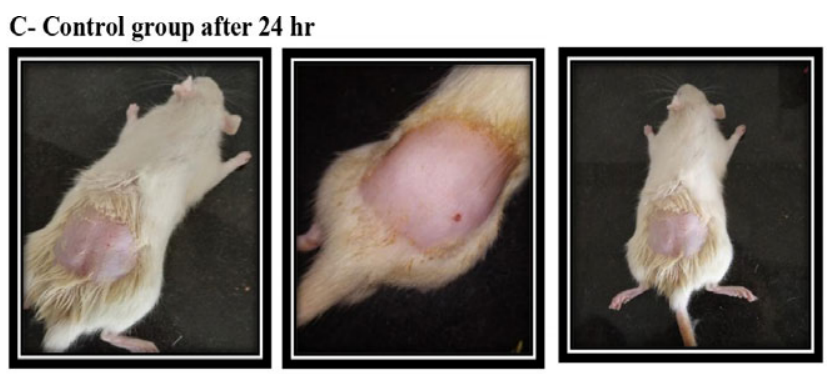

D- Test group after $24 \mathrm{hr}$
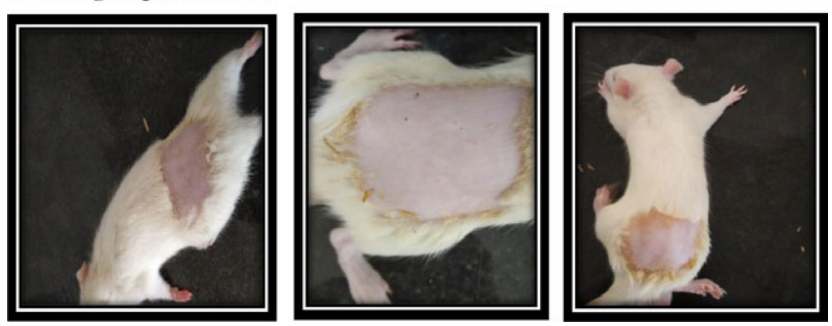

Figure 8: Skin irritaion test of Control and Test group after $24 \mathrm{hr}$.

zone of inhibition observed in case of drug gel without surfactants and linseed oil (34 mm). [Figure 4]

\section{Stability study}

Optimized formulation was examined after 30 days for any changes in $\mathrm{pH}$, rheological properties and drug release profiles. $\mathrm{pH}$ was found to be increased slightly. Viscosity was found to be increased at room temperature and then decreased at accelerated temperature. Drug release was found to be slightly decreased with temperature. Not much deviation was observed from optimized formulation F1, so it can be concluded that it showed acceptable stability on a given temperature and humidity. [Table 8]
Table 8: Stability study of optimized formulation F1.

\begin{tabular}{|c|c|c|c|}
\hline $\begin{array}{c}\text { Evaluation } \\
\text { Parameters }\end{array}$ & $\begin{array}{c}\text { Initial } \\
\text { day }\end{array}$ & $\begin{array}{c}\text { Room } \\
\text { temperature } \\
\left(\mathbf{2 5} 5^{\circ} \mathbf{C l ~ 6 0 \%}\right. \\
\mathbf{R H})\end{array}$ & $\begin{array}{c}\text { Accelerated } \\
\text { temperature } \\
\left(\mathbf{4} 0^{\circ} \mathbf{C} / \mathbf{6 5 \%} \mathbf{R H}\right)\end{array}$ \\
\hline $\mathrm{pH}$ & 6.48 & 6.51 & 6.77 \\
\hline Viscosity (cps) & 2325 & 2344 & 2287 \\
\hline Drug permeation (\%) & 63.50 & 62.20 & 59.08 \\
\hline
\end{tabular}

\section{CONCLUSION}

Luliconazole was successfully formulated in the form of microemulgel by using poly unsaturated fatty acid i.e., linseed oil with sodium alginate as gelling agent. Microemulsions were prepared by varying Tween 20 and Span 20 concentration in four emulsions. E1 and E4 were selected as optimized emulsion based on surface area distribution of globules (MA), PDI and physical stability. E1 showed globule area of $273.7 \mathrm{~nm}$ with 0.632 PDI and E4 showed globule area of $189.6 \mathrm{~nm}$ with PDI of 0.197. E1 and E4 showed good physical stability. Microemulgel was prepared by incorporation of $\mathrm{E} 1$ and $\mathrm{E} 4$ emulsion in formulation F1, F2, F3 and F4, F5, F6 respectively. Concentration of sodium alginate was varied in $2 \%, 4 \%$ and $6 \%$. The prepared microemulgel was pleasant in appearance and showed drug content ranged from $74.77 \%$ to $95.49 \%$. pH of all the formulations was within a range of 5.54 to 6.71 which is in accordance with skin $\mathrm{pH}$ indicating compatibility with skin. The viscosity of all formulations ranged from 2325 to $8850 \mathrm{cps}$. All formulations showed pseudoplastic behaviour. Spreadability values ranged from 2.6 to $3.7 \mathrm{gm} . \mathrm{cm} / \mathrm{sec}$. All the formulations belong to fluid gel category. The percentage cumulative drug permeation was found to be in the range of $51.93 \%$ to $63.50 \%$ after $5 \mathrm{hr}$. F1 formulation was selected as optimized formulation based on drug content, viscosity and percentage cumulative drug permeation. Skin irritation test showed that formulation is safe for use since it showed no signs of irritation. Optimized formulation F1 showed $38 \mathrm{~mm}$ zone of inhibition as compared to pure gel with $34 \mathrm{~mm}$ indicating its good antifungal activity. Acceptable stability profile was observed after subjecting the formulation to various conditions of temperature and humidity. Hence, it can be concluded that luliconazole microemulgel prepared with linseed oil and sodium alginate can be a choice for topical antifungal treatment. 


\section{ACKNOWLEDGEMENT}

The authors are very much grateful to the Principal KLE College of Pharmacy for providing necessary facilities to carry out the research work.

\section{CONFLICT OF INTEREST}

The authors declare no conflicts of interest.

\section{ABBREVIATIONS}

API: Active Pharmaceutical Ingredient; CLA: Cumulative Loss Added; CDP: Cumulative Drug Permeation; Min: Minutes; Hrs: Hours; Sec: Seconds; mg: Milligram; ml: Milliliter; $\boldsymbol{\mu g : ~ M i c r o ~ g r a m ; ~ g m : ~ G r a m s ; ~ n m : ~}$ Nanometer; m: Meter; cm: Centimeters; cps: Centipoise; i.e.: That is; ME: Microemulsion; RH: Relative Humidity; rpm: Revolutions per minute; UV: Ultra-violet; w/w: weight by weight; PEG: Polyethylene glycol; $\mathbf{R}^{2}$ : Regression coefficient; ZOI: Zone of inhibition.

\section{REFERENCES}

1. Sah SK, Badola A, Nayak BK. Emulgel: Magnifying the application of topical drug delivery. Indian Journal of Pharmaceutical and Biological Research. 2017;5(1):25-33.

2. Madhav S, Gupta D. A review on microemulsion based system. International Journal of Pharmaceutical Sciences and Research. 2011;2(8):188-94.
3. Ghosh PK, Murthy RS. Microemulsions: A potential drug delivery system. Current Drug Delivery. 2006;3(2):167-80.

4. Chandra A, Sharma PK. Microemulsions: An overview. Pharmainfo Net. 2008;6(2):12-7.

5. Haneefa KM, Easo S, Hafsa PV, Mohanta GP, Nayar C. Emulgel: An advanced review. Journal of Pharmaceutical Sciences and Research. 2013;5(12):254-8.

6. Nelson MM, Martin AG, Hefferman MP. Superficial fungal infections: Dermatophytosis, onychomycosis, tinea nigra, Piedra. Dermatology in General Medicine. 2005;6(2):3-11.

7. Kansagra $\mathrm{H}$, Mallick S. Microemulsion-based antifungal gel of luliconazole for dermatophyte infections: Formulation, characterization and efficacy studies. Journal of Pharmaceutical Investigation. 2015;2(1):2-12.

8. Scher RK, Nakamura N, Tavakkol A. Luliconazole: A review of a new antifungal agent for the topical treatment of onychomycosis. Mycosis Journal of Diagnosis, Therapy and Prophylaxis of Fungal Diseases. 2013;1(1):390-3.

9. Abd-allah FI, Dawaba HM, Ahmed AMS. Development of a microemulsionbased formulation to improve the availability of poorly water-soluble drug. Drug Discovery Ther. 2010;4(4):257-66.

10. Chandra A, Sharma PK, Irchhiaya R. Microemulsion based hydrogel formulation for transdermal delivery of Dexamethasone. Asian Journal of Phramaceutics. 2009;30-6.

11. Shankar D, Gajanan S, Suresh J, Dushyant G. Formulation and Evaluation of Luliconazole Emulgel for Topical Drug Delivery. International Research Journal of Science and Engineering. 2018;2(2):85-90.

12. Kaur LP, Guleri TK. Topical Gel: A Recent Approach for Novel Drug delivery. Asian Journal of Biomed Pharm Sci. 2013;3(17):1-5.

13. Verma NS, Maheshwari PV, Navya M, Reddy SC, Shivakumar HG, Gowda DV. Calcipotriol delivery into the skin as emulgel for effective permeation. Saudi Pharmaceutical Journal. 2014;22(6):591-9.

14. Khullar R, Kumar D, Seth N, Saini S. Formulation and evaluation of mefenamic acid emulgel for topical delivery. Saudi Pharmaceutical Journal. 2012;20(1):63-7.

15. Sabale V, Vora S. Formulation and Evaluation of microemulsion based hydrogel for topical delivery. International Journal of Pharmaceutical Investigation. 2012;2(3):140-9.

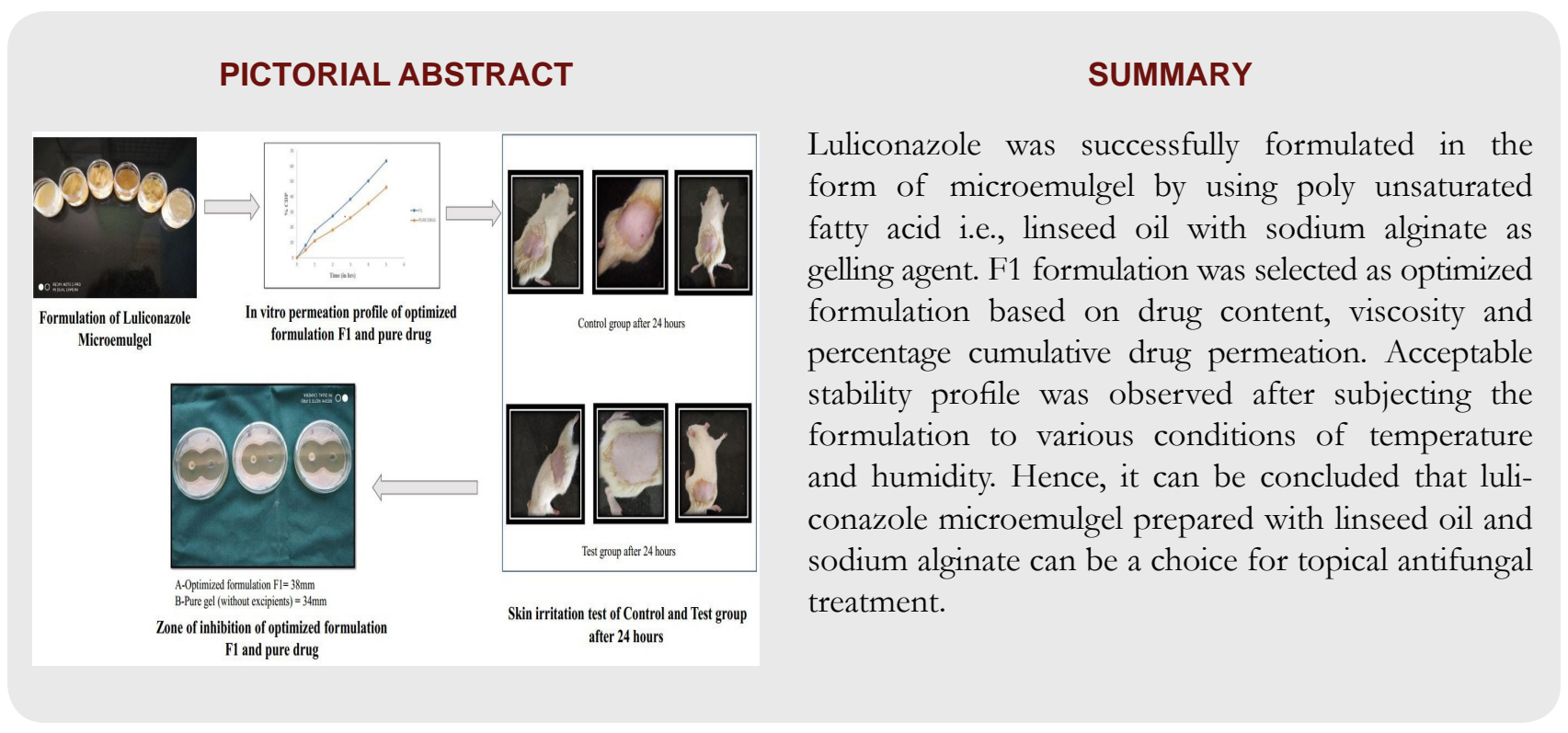




\section{About Authors}

Dr. Panchaxari M. Dandagi, is Professor in the Department of Pharmaceutics, KLE College of Pharmacy, (A Constituent unit of KAHER), Belagavi.

Ms. Pratibha Pandey was a Post graduate research scholar, completed her PG in the Department of Pharmaceutics, KLE College of Pharmacy, (A Constituent unit of KAHER), Belagavi.

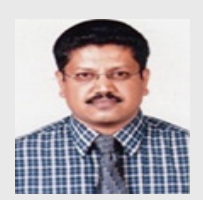

Dr. Anand P. Gadad, is Professor and HOD in the Department of Pharmaceutics, KLE College of Pharmacy, (A Constituent unit of KAHER), Belagavi.

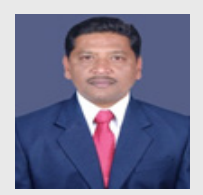

Dr. Vinayak S. Mastiholimath, is Professor in the Department of Pharmaceutical Quality Assurance, KLE College of Pharmacy, (A Constituent unit of KAHER), Belagavi.

Cite this article: Dandagi PM, Pandey P, Gadad AP, Mastiholimath VS. Formulation and Evaluation of Microemulsion Based Luliconazole Gel for Topical Delivery. Indian J of Pharmaceutical Education and Research. 2020;54(2):293301. 